\title{
Influence of SARS-CoV-2 infection on thyroid gland function: The current knowledge
}

\author{
Agata Czarnywojtek ${ }^{1,2, A-D}$, Alicja Ochmańska ${ }^{1,2, A, F}$, Małgorzata Zgorzalewicz-Stachowiak3, ,E,F,

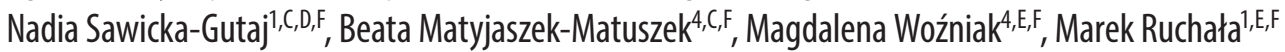 \\ ${ }^{1}$ Chair and Department of Endocrinology, Metabolism and Internal Medicine, Poznan University of Medical Sciences, Poland \\ 2 Department of Pharmacology, Poznan University of Medical Sciences, Poland \\ ${ }^{3}$ Department of Health Prophylaxis, Poznan University of Medical Sciences, Poland \\ ${ }^{4}$ Chair and Department of Endocrinology, Diabetology and Metabolic Diseases, Medical University of Lublin, Poland \\ A - research concept and design; $\mathrm{B}$ - collection and/or assembly of data; $\mathrm{C}$ - data analysis and interpretation; \\ $D$ - writing the article; $E$ - critical revision of the article; $F$ - final approval of the article
}

Address for correspondence

Małgorzata Zgorzalewicz-Stachowiak

E-mail: neuro@ump.edu.pl

Funding sources

None declared

Conflict of interest

None declared

Received on April 15, 2021

Reviewed on June 9, 2021

Accepted on June 30, 2021

Published online on July 20, 2021

\section{Cite as}

Czarnywojtek A, Ochmańska A, Zgorzalewicz-Stachowiak M,

et al. Influence of SARS-COV-2 infection on thyroid gland

function: The current knowledge. Adv Clin Exp Med.

2021;30(7):747-755. doi:10.17219/acem/139622

DOI

10.17219/acem/139622

Copyright

Copyright by Author(s)

This is an article distributed under the terms of the

Creative Commons Attribution 3.0 Unported (CC BY 3.0)

(https://creativecommons.org/licenses/by/3.0/)

\begin{abstract}
The paper summarizes the current knowledge about the influence of SARS-COV-2 on the thyroid gland and benign thyroid diseases, with emphasis on the situation in Poland. Based on the latest scientific literature published up to May 1, 2021 and the PubMed, Google Scholar, EMBASE and Web of Science database searches, keywords related to SARS-CoV-2 and its impact on the thyroid gland and benign thyroid diseases were searched. COVID-19-related thyroid disorders include non-thyroid syndrome, hypothyroidism and thyrotoxicosis. The authors paid special attention to the treatment of thyroid disease during the pandemic. The emphasis was on radioiodine therapy, which is of high clinical value due to the lower risk of neutropenia or agranulocytosis. It is currently unknown whether COVID-19 may lead to de novo thyroid dysfunction or if it can aggravate an existing thyroid disease. Patients with uncontrolled thyrotoxicosis are in a risk group for complications (e.g., cytokine storm) from any infection (especially from SARS-CoV-2 infection). Moreover, this group of patients should receive more extensive care, bearing in mind the neutropenia from taking antithyroid drugs, which may mask the symptoms of COVID-19.
\end{abstract}

Key words: therapy, hyperthyroidism, hypothyroidism, autoimmune thyroid disease, COVID-19 


\section{Introduction}

Coronavirus disease 2019 (COVID-2019) is an acute respiratory infectious disease caused by SARS-CoV-2 (severe acute respiratory syndrome corona virus 2). As evidenced, both SARS-CoV-2 and SARS-CoV spike (S) glycoproteins found on the envelope of the virus demonstrate affinity toward human angiotensin-converting enzyme 2 (ACE2). The carboxypeptidase ACE2 was identified as the entry host cell receptor for SARS-CoV-2. ${ }^{1,2}$ The world first heard of COVID-19 on January 3, 2020, when Chinese officials reported to the World Health Organization (WHO) about anomalous pneumonia affecting 44 patients in Wuhan (Hubei Province) and it was recognized as a "public health emergency of international concern". ${ }^{3}$ The first cases were vendors in the Huanan seafood market. A series of illnesses initiated a pandemic of the disease, in which the so-called "cytokine storm" and, consequently, multi-organ damage occurs. ${ }^{4}$ COVID-19 has become a considerable threat, especially among the elderly, including those with chronic diseases (diabetes, heart diseases, respiratory diseases, cancer) and pregnant women. Despite the various precautions taken by people (face masks, face shields, self-isolation, zoning), the SARS-CoV-2 virus causing COVID-19 spread at a geometric rate. ${ }^{5-11}$ Because of the global increase in morbidity, coronavirus disease 2019 was recognized as a global pandemic by the WHO on March 11, 2020. ${ }^{12}$ Severe acute respiratory syndrome (SARS) is an infectious condition caused by the SARS-CoV virus, belonging to the Coronaviridae family. ${ }^{8,13}$ SARS-CoV-2 has been found in the respiratory system (trachea, lungs), skeletal system (spine), digestive system (pancreas, liver, stomach, small intestine), distal convoluted renal tube, sweat glands, endocrine system (parathyroid, pituitary, adrenal gland), and central nervous system (cerebrum). It has not been detected in the heart, aorta, cerebellum, lymph node, bone marrow, esophagus, muscle, spleen, ovary, uterus, testis, and thyroid gland. ${ }^{14-16}$

\section{Objectives}

The purpose of this article is to present the latest data on the impact of COVID-19 on the thyroid gland (with emphasis on benign thyroid disease) based on a review of the current literature.

\section{Methodology}

A literature search has been conducted with PubMed, Google Scholar, EMBASE, and Web of Science (most recent literature search: May 1, 2021) using the following search terms: "thyroid disease and COVID-19 (SARS-CoV-2)", "autoimmune thyroid disease and coronavirus", "antithyroid therapy and COVID-19", "COVID-19 and hypothalamic-pituitary-adrenal axis", and "COVID-19 and clinical implications".

\section{SARS-CoV-2 and the hypothalamic- pituitary-thyroid axis and thyroid hormones}

It has been observed that an infection caused by SARSCoV-2 impacts the nervous system by affecting the cranial nerves and resulting in the loss of the senses of smell and taste. ${ }^{16}$ A retrospective analysis by Chen et al. ${ }^{17}$ in 50 COVID-19 patients showed that the serum levels of thyroid-stimulating hormone (TSH) and total triiodothyronine (T3) were significantly lower compared to the control group $(\mathrm{n}=54)$. The decrease in TSH levels observed in COVID-19 patients was caused by chronic stress with coexisting hypoxemia. Secondly, glucocorticoids were administered to $62 \%$ of patients at a dose of $57.3 \mathrm{mg}$ of methylprednisolone per day. Moreover, the serum concentrations of T3 and TSH were lower in patients with more severe the course of COVID-19 ( $\mathrm{p}<0.001$ ). However, no correlation was found between the severity of the disease and the concentration of total thyroxine (T4). No significant differences were found in the recovered patients between TSH and TH (thyroid hormones) levels in the control group, and affected by COVID-19.

Research by Wang et al. ${ }^{13}$ found that COVID-19 extensively damages the thyroid gland (follicular, epithelial, parafollicular cells). The observations of Wei et al. were conducted on the endocrine cells in the adenohypophysis of SARS-CoV-2-infected patients (autopsies, $\mathrm{n}=5$ ), where the reduced staining intensity of immunoreactivity and positive TSH cells (including growth hormone and adrenocorticotropic hormone) were observed, while an increase in signal intensity was observed in the case of prolactin, luteinizing hormone, and follicle-stimulating hormone. It is likely that the COVID-19 infection changes TSH secreting cells in the pituitary (the endocrine cells of the adenohypophysis).${ }^{18}$ Apart from destroying the thyroid cells, this inhibits the activity of deiodinase type I (D1) (resulting from the euthyroid sick syndrome, ESS), and downregulation at the hypothalamic-pituitary-thyroid (HPT) axis level is observed.

It has been reported by Ur et al. ${ }^{19}$ that SARS-CoV-2 can spread through nerve axons (the facial nerve, the glossopharyngeal nerve, the vagus nerve) due to the high expression of ACE2 and the high levels of the virus that are present in the oropharyngeal region. These nerves are located in the nucleus tractus solitarius (NTS). They facilitate the spread of the infection to NTS and lead to a cytokine storm damaging the cholinergic transmitter of the cholinergic anti-inflammatory and hypothalamicpituitary-adrenal (HPA) pathway. During the cytokine storm caused by SARS-CoV-2, increased levels of interleukin (IL)-6, IL-7, tumor necrosis factor (TNF), the soluble form of the $\alpha$-chain of the IL-2 receptor, and inflammatory chemokines (CCL2, CCL3, CXCL10) are observed. ${ }^{20}$

The impact of SARS-CoV-2 on TSH secreting cells is significant, leading to decreased concentrations of TSH and, 
thus, the observed disturbance of the pituitary endocrine axis feedback loops. The changes to the TSH secreting cells could occur through 4 mechanisms: direct damage to the pituitary gland by SARS-CoV-2; an indirect mechanism - the influence of pro-inflammatory cytokines ${ }^{14,16-18,21,22}$ and the so-called "cytokine storm"; 19 chronic stress caused by hypoxia; and the impact of the certain group of pharmaceuticals such as glucocorticoids (including methylprednisolone). ${ }^{21,22}$

In addition, expression of the SARS-CoV-2 ACE 2 receptor in thyroid follicular cells was increased; it was observed in minimal amounts in the hypothalamus as well. ${ }^{22-26}$ The serum ACE level was directly correlated with 3,5,3'-T3 and $\mathrm{T} 4,{ }^{26}$ which suggests it could be useful for exploring peripheral thyroid hormone action. Moreover, the study by Rotondi et al. ${ }^{27}$ has shown that as the messenger RNA (mRNA) encoding for the ACE2 receptor is expressed in thyroid follicular cells, the thyroid then becomes a potential target for SARS-CoV-2 entry.

\section{COVID-19 and euthyroid sick syndrome}

Severe respiratory infection caused by SARS-CoV-2 is associated with ESS, known as low T3 syndrome or non-thyroidal illness syndrome (NTIS), ${ }^{14,15}$ which disrupts the HPT axis, leading to hypothalamitis (central hypothyroidism). ${ }^{16-18}$ The mechanism of the emergence of ESS as a severe systemic disease can be distinguished as 2 phases: phase I - acute (inhibition of the activity of $\mathrm{D} 1$ resulting in reduced conversion of $\mathrm{T} 4$ to $\mathrm{T} 3$, increased metabolism of $\mathrm{TH}$ and decreased production of TH-binding proteins (e.g., albumin and thyroid-binding globulin), reduction of pulsatile TSH secretion); and phase II - chronic, in which there is a decrease in thyrotropin-releasing hormone (TRH) secretion (which results in the lowering of TSH and an insufficient supply of calories) and TSH (an increase in the levels of IL- 6 and IL-18 cytokines and TNF- $\alpha) .{ }^{15,17}$ In our opinion, neurological disorders (behavioral disorders, speech, olfactory disorders, taste disorders), which occur during the infection, but are nonetheless transient, can be compared to the "Polar T3 Syndrome" which occurs among "long-term explorers" in Antarctica. ${ }^{28}$ Indeed, in extreme cold, so much T3 is required to regulate body temperature that the brain is left with a less than an adequate supply making it slow, forgetful, unfocused, and moody. One of the most significant effects that it is advisable to note is neurological functions, including Polar explorers' speech, which tends to fail frequently.

Recent research by Lui et al. ${ }^{29}$ demonstrated that NTIS may be present in patients with severe COVID-19 symptoms as well as in patients with mild or moderate cases, who do not always require intensive care. The same researchers have shown that patients with NTIS had lower free triiodothyronine (fT3)/free thyroxine (fT4) and an indirect index of deiodinase activity converting T4 to T3. ${ }^{15}$ However, it was observed that the inflammatory markers (C-reactive protein (CRP) and erythrocyte sedimentation rate) and serum enzymatic markers of tissue damage (aspartate aminotransferase and lactate dehydrogenase) were increased, whereas cycle threshold values did not change. A previous retrospective study found that patients who died from COVID-19 had lower fT3 on admission than those who survived. . $^{30,31}$

\section{COVID-19 and autoimmune thyroid disease}

Nowadays, it is assumed that for the occurrence of autoimmune thyroid disease (AITD), including Graves' disease (GD) and Hashimoto thyroiditis (HT), coexisting endogenous factors such as genetic, intrathyroidal and exogenous (environmental) play a pivotal role. Some of the factors that may induce an immune response typical of GD are: iodine overdose, pregnancy (especially in the postpartum period), certain medications, radioiodine (RAI) therapy, tobacco smoke, stress, and bacterial and viral infections (including Epstein-Barr, hepatitis $\mathrm{C}$ virus (HCV) and parvoviruses). ${ }^{32-35}$

The AITD, which may manifest itself in the form of hypothyroidism or hyperthyroidism, does not require patients to mandatory self-isolate during the pandemic unless associated with idiosyncratic drug-induced neutropenia (IDIN) or post-antithyroid drugs (ATDs) - agranulocytosis. ${ }^{35}$ In the case of IDIN, the help of an endocrinologist should be immediate, which, in the current situation in Poland, when healthcare professionals are involved in fighting the COVID-19 pandemic, might be significantly challenging. Therefore, nowadays, isotope therapy (which will be discussed in detail later) is highly appreciated by professionals. Also, the frequent checkups that the patients then need to undergo both in hospital and at the clinic additionally expose patients to potential SARS-CoV-2 infection. Moreover, as Dworakowska and Grossmann. ${ }^{36}$ described, patients with IDIN belong to the high-risk group. In the UK, it has been reported that discussions with employers from various work environments are ongoing. This has a significant impact on employees who need to self-isolate (and possibly work from home) and those patients who have to continue to go to work, with the emphasis on warning patients taking antithyroid medications about the possible adverse effects of IDIN and recommending that they should seek immediate medical attention even for a fever or a sore throat.

It is now mandatory that patients with COVID-19 symptoms and coexisting GD and hyperthyroidism stay at home to self-quarantine for at least 10 days, which is no different to people with no coexisting thyroid dysfunction. 
With decreasing numbers of healthcare professionals available in hospital facilities to help minimize the spread of the virus, one solution is to carry out online consultations using phone or video calls (telemedicine). European Thyroid Association (ETA) ${ }^{37}$ and American Thyroid Association (ATA $)^{38}$ guidelines currently exist for the diagnosis and management of thyroid diseases; however, as Dworakowska and Grossmann ${ }^{36}$ state, some analogies and helpful tips on how to treat patients can be drawn from the experience of rheumatologists; such analogies also apply to autoimmune diseases, including, for example, rheumatoid arthritis. ${ }^{39}$ According to FigueroaParr et al. ${ }^{40}$ and Dworakowska and Grossmann, ${ }^{36} \mathrm{pa}-$ tients suffering from COVID-19 with coexisting AITD are not included in the high-risk group. There has been no evidence that patients with AITD are more likely to be infected by SARS-CoV-2 or are at risk of developing the more severe COVID-19 disease. ${ }^{25,36}$ However, according to Boelaert et al., ${ }^{41}$ patients with Graves' ophthalmopathy (GO), who actively undergo active immunosuppressive therapy, may be particularly at risk.

\section{Hypothyroidism}

Treating hypothyroidism during the COVID-19 pandemic has not changed significantly. Therefore, substitution of levothyroxine (L-T4) at the same dose (the same as the usual treatment) is recommended. ${ }^{40,42}$ However, it should be noted that in the era of the COVID-19 outbreak in Poland, access to an endocrinologist and diagnostic tests may be difficult. In Poland and other European countries, patients with COVID-19 symptoms are recommended a new form of consultation, e.g., 1) online chat, 2) via email, 3) phone, and, from January 1, 2020, 4) electronic prescriptions. ${ }^{6}$

The problem of neonatal screening for congenital hypothyroidism is different, as these tests need to be carried out with special care, and any delays in performing them should be avoided. ${ }^{43}$

Decreased serum TSH levels are observed among pregnant women of all populations. However, differences between ethnic and racial groups have been observed. A study conducted in Europe and the US showed that the upper reference limit for serum TSH concentration is $2.5 \mathrm{mU} / \mathrm{L}$ in the $1^{\text {st }}$ trimester and $3.0 \mathrm{mU} / \mathrm{L}$ in the $2^{\text {nd }}$ and $3^{\text {rd }}$ trimester. ${ }^{4,45}$ However, a study conducted in China on 4800 women who were between 7 and 12 weeks pregnant, found that the upper reference limit only changed from $5.31 \mathrm{mU} / \mathrm{L}$ to $4.34 \mathrm{mU} / \mathrm{L} .{ }^{45}$ Thus, we can conclude that with the rise in COVID-19 cases, the therapy for hypothyroid disease for pregnant and postpartum women should be individualized, but according to the guidelines of the ATA, the L-T4 dose should be increased by 2 tables of the same dose weekly. ${ }^{44}$ Thus, thyroid function tests should be measured according to the population-based and trimester-specific reference ranges. ${ }^{44,45}$

\section{Hyperthyroidism}

A recent study (retrospective analysis) conducted by Lania et al. ${ }^{46}$ in 287 consecutive patients ( 94 females and 193 males) showed a relationship between a high risk of thyrotoxicosis and the SARS-CoV-2 infection. Additional publications support an association between $\mathrm{CO}-$ VID-19 infection and overt and subclinical thyrotoxicosis, as well as with subacute thyroiditis. ${ }^{47,48}$ COVID-19 may exacerbate GD. ${ }^{17,49}$ A cohort study carried out by Khoo et al. ${ }^{50}$ observed a small transient decrease in serum TSH and fT4 levels (which could also be considered to mimic hyperthyroidism) in patients with COVID-19 infection. However, the most likely explanation of this would be the nonthyroidal illness syndrome observed in some of the patients.

For the treatment of hyperthyroidism, antithyroid drugs (ATDs), including thiamazole (methimazole - MMI) and propylthiouracil (PTU), remain the first choice. In addition, RAI therapy is an alternative method, especially for multiple focal lesions, when a patient refuses to consent to strumectomy and agranulocytosis after ATDs. In exceptional circumstances, performing a strumectomy should be considered in the case of GO disease or in toxic nodular goiter after achieving euthyroidism when a malignant process is suspected. However, we must be aware of the adverse effect of ATDs, such as IDIN (neutrophil count of $<1.0 \times 10^{9} / \mathrm{L}$ ) or agranulocytosis $\left(<0.5 \times 10^{9} / \mathrm{L}\right)$, which occurs in $0.2-0.5 \%$ of cases. ${ }^{46,51,52}$ Also, IDIN patients may have similar symptoms to patients with COVID-19 disease, such as a fever, mouth ulceration, a flu-like illness or a sore throat. Hence, it might be questionable whether, in view of this situation, patients should stay at home and undergo self-isolation or if they should visit an endocrinologist or general practitioner. Zhou et al. ${ }^{53}$ found that $50 \%$ of patients who died of COVID-19 had neutropenia which exacerbated the severity of the disease. Additionally, the authors observed that advanced age, high d-dimer levels (greater than $1 \mu \mathrm{g} / \mathrm{mL}$ ) and high Sequential Organ Failure Assessment (SOFA) scores may help clinicians with earlier identification of patients with a poor prognosis. Currently (and also before the global COVID-19 pandemic), an urgent full blood count measurement is recommended to check for IDIN and changing the drug, e.g., MMI to PTU, or discontinuing ATD treatment in neutropenic patients, as well as informing the patient about the results. ${ }^{54}$ On the other hand, COVID-19 infection alone can often lead to lymphopenia and thrombocytopenia. Therefore, the additional problem arises of what to do with a COVID-19 patient who has also developed thyrothoxicosis? Can ATDs be started in the hospital setting or given at home when RAI cannot be used due to COVID-19 infection? ${ }^{50-54}$

\section{Pregnant women with hyperthyroidism}

Pregnant women with hyperthyroidism should take special precautions against COVID-19, especially in later pregnancy, as the severe symptoms requiring hospital 
admission are relatively uncommon in young women of reproductive age. ${ }^{55}$ The standard therapy methods should be followed, i.e., PTU is recommended in the $1^{\text {st }}$ trimester of pregnancy (through to 16 weeks), followed by a switch to MMI (a dose ratio of 1:20, i.e., MMI $5 \mathrm{mg} /$ day = PTU $50 \mathrm{mg}$ twice daily) using the lowest dose of ATD possible. ${ }^{44}$ However, the physician should inform such patients about the potential teratogenic effects of $\mathrm{MMI}^{53}$ and aplasia cutis, ${ }^{43}$ as well as where methimazole/carbimazole embryopathy syndrome coexists with dysmorphic facies, ${ }^{57-60}$ channel or esophageal atresia, abdominal wall defects (e.g., umbilicocele) and other defects (i.e., of the urinary tract, eyes, and ventricular septum). ${ }^{61-64}$ It should be noted that while we can use block replace regimens (BRRs) in adults or children, this therapy method is prohibited in pregnant women. In pregnant women with COVID-19 infection, a higher susceptibility to both maternal and fetal immune complications has been observed. ${ }^{65}$ It has been demonstrated that COVID-19 may exacerbate as well as trigger autoimmune thyroid diseases, especially GD. ${ }^{17,49}$

\section{Rules for treating hyperthyroidism during the pandemic}

\section{Antithyroid drugs}

Titration therapy remains the treatment of choice (MMI or PTU). However, due to the COVID-19 pandemic and the lack of access to specialists in Poland and other countries, one of the recommended therapies is the BRR method introduced by Weetman et al. in 1994. ${ }^{66}$ Until now, this therapy method, widely used in the UK, has not been so widespread in Poland but only used by older and more experienced endocrinologists. The BBRs are especially recommended for patients at baseline or with recurrent thyrotoxicosis (regardless of etiology, e.g., GD with or without $\mathrm{GO}$, toxic multinodular goiter and amiodarone-induced thyrotoxicosis). ${ }^{66,67}$ For adults, when the serum fT4 concentration is at the upper normal limit of $30 \mathrm{pmol} / \mathrm{L}$ (fT4 ULN - $30 \mathrm{pmol} / \mathrm{L})$, treatment should begin with $20 \mathrm{mg}$ carbimazole or $15 \mathrm{mg}$ methimazole. In the case of fT4 levels of $30-60 \mathrm{pmol} / \mathrm{L}$ or $>60 \mathrm{pmol} / \mathrm{L}$, the starting point should be a double dose (40 mg carbimazole/30 mg methimazole). At the same time, the patient must be informed about any side effects such as liver dysfunction, neutropenia, agranulocytosis, or congenital disabilities. After 4 weeks of the treatment, TH levels should be checked while continuing ATDs (40 mg carbimazole/30 mg methimazole) at the same dose for all patients. At the same time, L-T4 should be added ( $75 \mu \mathrm{g}$ if body weight $(\mathrm{BW}) \leq 55 \mathrm{~kg}$, and $100 \mu \mathrm{g}$ if BW $>55 \mathrm{~kg}$ ). The exact algorithm for therapeutic management in both adults and children is presented in the publication by Boelaert et al. ${ }^{41}$

\section{Thyroidectomy}

The indications for performing surgery have not changed; only the pandemic itself, unfortunately, delays the implementation of this procedure. A delay of a few months does not seem to be life-threatening for patients. Alternatively, RAI therapy could be another treatment option.

\section{Radioiodine therapy}

Oral administration of RAI therapy is used to treat benign thyroid disease, which includes autoimmune hyperthyroidism (GD, mild GO), solitary hyperfunctioning thyroid nodule, toxic multinodular goiter (Plummer's disease), toxic adenoma (Goetsch's disease), and non-toxic goiter (patients with a large retrosternal goiter). ${ }^{68}$ In Poland, RAI deliveries to departments of endocrinology in Poznań and Lublin were only suspended for 3 weeks due to COVID-19, which did not negatively impact the wellbeing of patients. To date, these departments have been following the usual ways of working from before the global pandemic. However, to minimalize risk for our patients, we have slightly modified our protocol. We have stopped performing radioiodine uptake (RAIU), both in 5 and 24-hour time point (which allowed us to shorten the waiting time for treatment and thus reduce the number of patients). Patients were admitted to hospital for 1 day, during which all required laboratory tests were performed, including those for thyroid-stimulating hormone (TSH), TH (fT4, fT3), and thyrotropin receptor autoantibodies (TRAb) titers, as well as ${ }^{99 \mathrm{~m}} \mathrm{Tc}$ thyroid scintigraphy and thyroid ultrasound.

We followed the same practices from before the pandemic, excluding the RAI treatment, based on our 20 years of experience and the European Association of Nuclear Medicine guidelines, in line with the words of Stokkel et al.: "Uptake measurements are not absolutely required when fixed activities are used" ${ }^{69}$ It is noteworthy that our department (in Poznań) is the oldest center in Poland where RAI therapy is in use, being performed for the first time in 1956. We used the following fixed treatment regimen (fixed activity): from 5 (185 mBq) to $10 \mathrm{mCi}(370 \mathrm{mBq})$ to treat GD or mild GO; $15 \mathrm{mCi}(555 \mathrm{mBq}$ ) for toxic adenoma; from 10 $(370 \mathrm{mBq})$ to $20 \mathrm{mCi}(740 \mathrm{mBq})$ to treat toxic multinodular goiter; and in patients with large retrosternal goiter activity, $20 \mathrm{mCi}(740 \mathrm{mBq}$ ) (3 times at intervals of 3 months - total activity $60 \mathrm{mCi}=2220 \mathrm{MBq}$ ) was administered.

However, the epidemic influenced the more frequent use of ablative rather than fixed activity. Fixed activity often requires repeated doses, which nowadays is inconvenient for both patients and physicians. It should be emphasized that in the pandemic era, hypothyroidism after RAI treatment is the goal of our therapy and not a complication (studies in preparation). Based on our experience, the use of RAI therapy is of increasing importance in the global COVID-19 era, for example, in the case of IDIN after ATDs. In patients with GD, increased morbidity and mortality is observed, ${ }^{69,70}$ although RAI itself does not increase the death rate. ${ }^{71}$ However, there are still concerns regarding the influence of RAI therapy on the risk of malignancy. ${ }^{72}$

Currently (as already mentioned), we use RAI more frequently as the first-choice therapy, mostly because 
of the common adverse effect of ATDs - neutropenia (which also occurs in patients infected with SARS-CoV-2) - and, due to the long waiting time to see a specialist. While hypothyroidism after RAI therapy is not an adverse effect but a therapeutic objective about which a family doctor can safely advise, IDIN after ATDs, however, is a difficult challenge even for an experienced endocrinologist and nuclear physician. There is currently no scientific evidence that patients after RAI therapy or thyroidectomy are more likely to become infected with any virus, including the SARS-CoV-2 virus.

\section{Glucocorticoids and immunosuppressive and biological therapy}

Patients with GO treated with immunosuppressants (mycophenolate, azathioprine), biological agents (teprotumumab, rituximab and tocilizumab) or glucocorticoids (GCs) belong to vulnerable populations, and are at particularly higher risk from coronavirus. ${ }^{73}$ These patients are advised to self-isolate for as long as possible. ${ }^{74,75}$

It is evidenced that GCs can affect serum TSH levels in humans. A study by Samuels and $\mathrm{McDaniel}^{76}$ has shown that the physiological dose of hydrocortisone plays a pivotal role in the daily variations of serum TSH levels, with lower levels in the morning and higher levels at night. ${ }^{77}$ The impact of GCs on TSH is still uncertain. One possible hypothesis is that GCs can directly inhibit TSH-releasing factor in the hypothalamus. John et al. ${ }^{78}$ demonstrated that dexamethasone seems to suppress TSH release from thyrotropes in a protein kinase $\mathrm{C}$-dependent manner through the protein annexin 1. The GS receptors are located in the TRH neurons of male rats. ${ }^{72}$ Moreover, a straightforward evidence shows that high-dose GCs may decrease TRH mRNA expression in the paraventricular nucleus of the hypothalamus in humans. ${ }^{79}$ It is worth noting that the routine use of corticosteroids in COVID-19 patients complicates the diagnosis of thyroid function and the interpretation of some reports. As previously suggested, even low doses of corticosteroids can make interpretation of TSH levels much more difficult. ${ }^{80}$

A British study performed by the RECOVERY Collaborative Group ${ }^{81}$ demonstrated that dexamethasone could increase survival rates among hospitalized COVID-19 patients receiving either invasive mechanical ventilation or oxygen alone. However, no change in the survival rates was observed among those receiving no respiratory support. Hence, in the most recent WHO guidelines on drugs for COVID-19, ${ }^{82}$ systemic corticosteroids were recommended in patients with acute and critical COVID-19 but not in patients with mild COVID-19 symptoms.

Rituximab is an anti-CD20 antibody which depletes $B$ cells and became a second-line therapy for people with GO. ${ }^{83}$ Whereas the risk of opportunistic infections is higher in the long term, follow-up trials of rituximab in rheumatoid arthritis show that the risk is likely to be minimal in those patients with GO who are receiving low doses of this drug. ${ }^{84}$ Teprotumumab (an insulin-like growth factor1 (IGF1) receptor inhibitor) has recently been approved as a therapy for moderate-to-severe GO. Preliminary data have shown that no significant increase in the rate of infections was observed in patients on teprotumumab. ${ }^{84}$ It could be an interesting alternative to GCs during the COVID-19 pandemic, but unfortunately, the high costs and low availability can limit the number of patients who may take advantage of this therapy.

To reduce the signs of ophthalmopathy, especially in times of a global pandemic, it is essential and advisable to strictly discontinue cigarette smoking and reinforce recommendations, including selenium supplementation. ${ }^{85}$ Patients with GO may be more susceptible to developing symptomatic forms of COVID-19 (where SARS-CoV mRNA expression has been found). ${ }^{86}$

\section{Limitations}

The main limitation of our study is that no follow-up data were available to analyze the effects of COVID-19 specifically on the thyroid gland. Secondly, the mechanism by which COVID-19 affects thyroid gland function is not well understood and requires further investigation at the molecular level. Thirdly, it is necessary to observe the disease for a longer period to determine whether it increases the incidence of autoimmune diseases of the thyroid gland (GD and HT). However, there are already preliminary meta-analyses that deal with this issue.

\section{Conclusion}

In conclusion, COVID-19 can be called the plague of the $21^{\text {st }}$ century, and we may have to live with it until the end of our existence; perhaps, it will be the norm to take precautionary measures. It is currently unknown whether COVID-19 may lead to de novo thyroid dysfunction or at least aggravate an existing thyroid disease. There is no scientific evidence that people with poorly controlled thyroid disease are at higher risk of viral infections. However, it is likely that patients with uncontrolled thyroid dysfunction, especially those with thyrotoxicosis, may be at higher risk of complications (e.g., cytokine storm) from any infection. It should be noted that this group of patients should receive more extensive care, bearing in mind the neutropenia after ATDs, which may mask the symptoms of COVID-19 infection. The COVID-19 pandemic has slightly changed our approach to the BRRs method, which is not commonly used in Poland. As already noted, the role of RAI therapy in the global pandemic has become of greater importance, especially when taking neutropenia into account - the adverse effect of ATDs, which may mask the symptoms of COVID-19 disease caused by SARSCoV-2. It should be emphasized that special precautions 
during the global COVID-19 pandemic should be taken for patients with GO undergoing immunosuppressive medication and pregnant women with hyper- and hypothyroidism.

The COVID-19 pandemic has changed health provision drastically. The use of telemedicine could, in certain situations, lead to improved access to care, shortening waiting times to see a specialist as well as minimalizing the risk of person-to-person transmission of COVID-19. As a result, the burden on healthcare systems could be reduced, but we must remember that this solution is not ideal and there can be a risk of misdiagnosis.

\section{ORCID iDs}

Agata Czarnywojtek (1) https://orcid.org/0000-0003-3595-8449 Alicja Ochmańska (10) https://orcid.org/0000-0001-7892-6135 Małgorzata Zgorzalewicz-Stachowiak

(1) https://orcid.org/0000-0001-9260-3674

Nadia Sawicka-Gutaj (1) https://orcid.org/0000-0003-1510-4702 Beata Matyjaszek-Matuszek (1) https://orcid.org/0000-0001-7386-8087 Magdalena Woźniak (i) https://orcid.org/0000-0003-0442-7899 Marek Ruchała (1) https://orcid.org/0000-0002-6296-7220

\section{References}

1. Gorbalenya $A E$, Baker $S C$, Baric RS, et al. Severe acute respiratory syndrome-related coronavirus. The species and its viruses: A statement of the Coronavirus Study Group. Nat Microbiol. 2020;5:536-544. doi:10.1038/s41564-020-0695-z

2. Hossain MF, Hasana S, Mamun AA, et al. COVID-19 outbreak: Pathogenesis, current therapies, and potentials for future management. Front Pharmacol. 2020;16(11):563478. doi:10.3389/fphar.2020.563478

3. WHO: Coronavirus disease (COVID-19) pandemic. https://www.who. int/emergencies/diseases/novel-coronavirus-2019. Accessed December 23, 2021.

4. Hui DS, Azhar El, Madani TA, et al. The continuing 2019-nCoV epidemic threat of novel coronaviruses to global health: The latest 2019 novel coronavirus outbreak in Wuhan, China. Int J Infect Dis. 2020;91: 264-266. doi:10.1016/j.ijid.2020.01.009

5. Mehta P, McAuley DF, Brown M, Sanchez E, Tattersall RS, Manson JJ; HLH Across Speciality Collaboration, UK. COVID-19: Consider cytokine storm syndromes and immunosuppression. Lancet. 2020;395(10229): 1033-1034. doi:10.1016/S0140-6736(20)30628-0

6. Art. 96a Pf. https://www.lexlege.pl/prawo-farmaceutyczne/art-96a/ https://lexlege.pl/prawo-farmaceutyczne/art-96a/. Accessed February $1,2021$.

7. Studdert DM, Hall MA. Disease control, civil liberties, and mass testing: Calibrating restrictions during the Covid-19 pandemic. NEngl J Med. 2020;9;383(2):102-104. doi:10.1056/NEJMp2007637

8. Guo Y, Korteweg C, McNutt MA, Gu J. Pathogenetic mechanisms of severe acute respiratory syndrome. Virus Res. 2008;133(1):4-12. doi:10.1016/j.virusres.2007.01.022.

9. Guo YR, Cao QD, Hong ZS, et al. The origin, transmission and clinical therapies on coronavirus disease 2019 (COVID-19) outbreak: An update on the status. Mil Med Res. 2020;13;7(1):11. doi:10.1186/ s40779-020-00240-0

10. Docea AO, Tsatsakis A, Albulescu D, et al. A new threat from an old enemy: Reemergence of coronavirus. Int J Mol Med. 2020;45(6): 1631-1643. doi:10.3892/ijmm.2020.4555

11. Albano F, Bertagna $M$, Bertolia $G$, et al. Incidental findings suggestive of Covid-19 in asymptomatic patients undergoing nuclear medicine procedures in a high prevalence region. J Nucl Med. 2020;61(5): 632-636. doi:10.2967/jnumed.120.246256

12. World Health Organization. WHOTimeline-COVID-19.https://www.who. int/news-room/detail/27-04-2020-who-timeline-covid-19. Accessed January 15, 2021.

13. Wang W, Ye YX, Yao H. Evaluation and observation of serum thyroid hormone and parathyroid hormone in patients with severe acute respiratory syndrome. J Chin Antituberculous Assoc. 2003;25:232-234.
14. Ding $Y, H e L$, Zhang $Q$, et al. Organ distribution of severe acute respiratory syndrome (SARS) associated coronavirus (SARSCoV) in SARS patients: Implications for pathogenesis and virus transmission pathways. J Pathol. 2004;203(2):622-630. doi:10.1002/path.1560

15. Fliers $E$, Bianco AC, Langouche L, Boelen A. Thyroid function in critically ill patients. Lancet Diabetes Endocrinol. 2015;3(10):816-825. doi:10. 1016/S2213-8587(15)00225-9

16. Gu J, Gong E, Zhang B, et al. Multiple organ infection and the pathogenesis of SARS. J Exp Med. 2005;202(3):415-424. doi:10.1084/jem. 20050828

17. Chen $M$, Zhou W, Xu W. Thyroid function analysis in 50 patients with COVID-19: A retrospective study. Thyroid. 2021;31(1):8-11. doi:10.1089/ thy. 2020.0363

18. Wei L, Sun S, Zhang J, et al. Endocrine cells of the adenohypophysis in severe acute respiratory syndrome (SARS). Biochem Cell Biol. 2010;88(4):723-730. doi:10.1139/010-022

19. Ur A, Verma K. Cytokine storm in COVID-19:A neural hypothesis. ACSChem Neurosci. 2020;11(13):1868-1870. doi:10.1021/acschemneuro.0c00346

20. Merad $M$, Martin JC. Pathological inflammation in patients with COVID-19: A key role for monocytes and macrophages. Nat Rev Immunol. 2020;20;355-362. doi:10.1038/s41577-020-0331-4

21. Lechien JR, Chiesa-Estomba CM, De Siati DR, et al. Olfactory and gustatory dysfunctions as a clinical presentation of mild-to-moderate forms of the coronavirus disease (COVID-19): A multicenter European study. Eur Arch Otorhinolaryngol. 2020;277(8):2251-2261. doi:10.1007/ s00405-020-05965-1

22. Pal R. COVID-19, hypothalamo-pituitary-adrenal axis and clinical implications. Endocrine. 2020;68(2):251-252. doi:10.1007/s12020-02002325-1

23. Pal R, Banerjee M. COVID-19 and the endocrine system: Exploring the unexplored. J Endocrinol Invest. 2020;43(7):1027-1031. doi:10.1007/ s40618-020-01276-8

24. Lazartigues E, Qadir MMF, Mauvais-Jarvis F. Endocrine significance of SARS-CoV-2's reliance on ACE2. Endocrinology. 2020;161(9):bqaa108. doi:10.1210/endocr/bqaa108

25. Li MY, Li L, Zhang Y, Wang XS. Expression of the SARS-CoV-2 cell receptor gene $A C E 2$ in a wide variety of human tissues. Infect Dis Poverty. 2020;9(1):45. doi:10.1186/s40249-020-00662-x

26. Smallridge RC, Rogers J, Verma PS. Serum angiotensin-converting enzyme: Alterations in hyperthyroidism, hypothyroidism, and subacute thyroiditis. JAMA. 1983;250(18):2489-2493. doi:10.1001/jama. 250.18.2489

27. Rotondi M, Coperchini F, Ricci G, et al. Detection of SARSCOV-2 receptor ACE-2 mRNA in thyroid cells: A clue for COVID-19-related subacute thyroiditis. J Endocrinol Invest. 2020;44(5):1085-1090. doi:10.1007/ s40618-020-01436-w

28. Reed HL, Silverman ED, Shakir KM, Dons R, Burman KD, O'Brian JT. Changes in serum triiodothyronine (T3) kinetics after prolonged Antarctic residence: The polar T3 syndrome. J Clin Endocrinol Metab. 1990;70(4):965-974. doi:10.1210/jcem-70-4-965

29. Lui DTW, Lee CH, Chow WS, et al. Thyroid dysfunction in relation to immune profile, disease status and outcome in 191 patients with COVID-19. J Clin Endocrinol Metab. 2020;3:dgaa813. doi:10.1210/ clinem/dgaa813

30. Chen T, Wu D, Chen $\mathrm{H}$, et al. Clinical characteristics of 113 deceased patients with coronavirus disease 2019: Retrospective study [published correction appears in BMJ.2020;368:m1295]. BMJ. 2020;368:1-12. doi:10.1136/bmj.m1091

31. Gao W, Guo W, Guo Y, et al. Thyroid hormone concentrations in severely or critically ill patients with COVID-19. J Endocrinol Invest. 2020;44(5):1031-1040. doi:10.1007/s40618-020-01460-w

32. Tomer $Y$, Huber A. The etiology of autoimmune thyroid disease: A story of genes and environment. J Autoimmun. 2009;32(3-4):231-239. doi:10.1016/j.jaut.2009.02.007

33. Tomer Y. Genetic susceptibility to autoimmune thyroid disease: Past, present, and future. Thyroid. 2010;20(7):715-725. doi:10.1089/ thy.2010.1644

34. Antonelli A, Ferrari SM, Ragusa F, et al. Graves' disease: Epidemiology, genetic and environmental risk factors and viruses. Best Pract Res Clin Endocrinol Metab. 2020;34(1):101387. doi:10.1016/j.beem.2020.101387

35. Brancatella A, Ricci D, Viola N, Sgrò D, Santini F, Latrofa F. Subacute thyroiditis after SARS-COV-2 infection. J Clin Endocrinol Metab. 2020; 105(7):dgaa276. doi:10.1210/clinem/dgaa276 
36. Dworakowska D, Grossman AB. Thyroid disease in the time of COVID-19. Endocrine. 2020;68(3):471-474. doi:10.1007/s12020-020-02364-8

37. European Thyroid Association. COVID-19: Information for patients with thyroid diseases. https://www.eurothyroid.com/news/covid19thyroid-diseases.html. Accessed February 1, 2021.

38. American Thyroid Association. Novel coronavirus (COVID-19) and the thyroid: Resources. https://www.thyroid.org/covid-19. Accessed February 1, 2021.

39. Conigliaro $P, D^{\prime}$ Antonio A, Pinto, et al. Autoimmune thyroid disorders and rheumatoid arthritis: A bidirectional interplay. Autoimmun Rev. 2020;19(6):102529. doi:10.1016/j.autrev.2020.102529

40. Figueroa-Parra GM, Aguirre-Garcia CM, Gamboa-Alonso CM, Camacho-Ortiz A, Galarza-Delgado DA. Are my patients with rheumatic diseases at higher risk of COVID-19? Ann Rheum Dis. 2020;79(6):839-840. doi:10. 1136/annrheumdis-2020-217322.

41. Boelaert K, Visser W, Taylor P, Moran C, Léger J, Persani L. Endocrinology In the time of COVID-19: Management of hyperthyroidism and hypothyroidism. Eur J Endocrinol. 2020;183(1): G33-G39. doi:10.1530/ EJE-20-0445

42. Chaker L, Bianco AC, Jonklaas J, Peeters RP. Hypothyroidism. Lancet. 2017:390(10101):1550-1562. doi:10.1016/S0140-6736(17)30703-1

43. Art. 96 a Pf. https://www.lexlege.pl/prawo-farmaceutyczne/art-96a/.

44. Stagnaro-Green A, Abalovich M, Alexander EK, et al; American Thyroid Association Taskforce on Thyroid Disease During Pregnancy and Postpartum. Guidelines of the American Thyroid Association for the diagnosis and management of thyroid disease during pregnancy and postpartum. Thyroid. 2011:21(10):1081-1125.

45. De Groot L, Abalovich M, Alexander EK, et al. Management of thyroid dysfunction during pregnancy and postpartum: An Endocrine Society clinical practice guideline. J Clin Endocrinol Metab. 2012; 97(8):2543-2565. doi:10.1210/jc. 2011-2803

46. Lania A, Sandri MT, Cellini M, Mirani M, Lavezzi E, Mazziotti G. Thyrotoxicosis in patients with COVID-19: The THYRCOV study. Eur J Endocrinol. 2020;183(4):381-387. doi:10.1530/EJE-20-0335

47. Brancatella A, Ricci D, Cappellani D, Sgrò VD, Santini F, Latrofa F. Is subacute thyroiditis an underestimated manifestation of SARS-CoV-2 infection? Insights from a case series. J Clin EndocrinolMetab. 2020;105(10):dgaa537. doi:10.1210/clinem/dgaa537

48. Sohrabpour S, Heidari F, Karimi E, Ansari R, Tajdini A, Heidari F. Subacute thyroiditis in COVID-19 patients. Eur Thyroid J. 2020;9(6):321-323. doi:10.1159/000511707

49. Mateu-Salat M, Urgell E, Chico A. SARS-COV-2 as a trigger for autoimmune disease: Report of two cases of Graves' disease after COVID-19. J Endocrinol Invest. 2020;43(10):1527-1528. doi:10.1007/s40618-02001366-7

50. Khoo B, Tan T, Clarke SA, et al. Thyroid function before, during and after COVID-19. J Clin Endocrinol Metab. 2020;106(2);e803-e811. doi:10. 1210/clinem/dgaa830

51. De Leo S, Lee SY, Braverman LE. Hyperthyroidism. Lancet. 2016;388 (10047):906-918. doi:10.1016/S0140-6736(16)00278-6

52. Burch HB, Cooper DS. Antithyroid drug therapy: 70 years later. Eur J Endocrinol. 2018;179(5):R261-R274. doi:10.1530/EJE-18-0678

53. Zhou F, Yu T, Du R, et al. Clinical course and risk factors for mortality of adult in patients with COVID-19 in Wuhan, China: A retrospective cohort study. Lancet. 2020;395(10229):1054-1062. doi:10.1016/S01406736(20)30566-3

54. Ross DS, Burch HB, Cooper DS, et al. American Thyroid Association guidelines for diagnosis and management of hyperthyroidism and other causes of thyrotoxicosis. Thyroid. 2016:26(10):1343-1421.

55. Terpos E, Ntanasis-Stathopoulos I, Elalamy I, et al. Hematological findings and complications of COVID-19. Am J Hematol. 2020;95(7): 834-847. doi:10.1002/ajh.25829.

56. Royal College of Obstetricians and Gynaecologists. Coronavirus (COVID-19). Infection in Pregnancy. https://www.rcog.org.uk/globalassets/documents/guidelines/2020-04-17-coronavirus-covid-19-infection-in-pregnancy.pdf.

57. Li C, Shan Z, Mao J, et al. Assessment of thyroid function during first-trimester pregnancy: What is the rational upperlimit of serum TSH during the first trimester in Chinese pregnant women? J Clin Endocrinol Metab. 2014;99(1):73-79. doi:10.1210/jc.2013-1674

58. Anderson SL, Olsen J, Laurberg P. Antithyroid drug side effects in the population and in pregnancy. J Clin Endocrinol Metab. 2016;101(4): 1606-1614.
59. Milham SJ, Elledge W. Maternal methimazole andcongenital defects in children. Teratology. 1972;5:125-126. doi:10.1002/tera.1420050117

60. Clementi M, Di Gianantonio E, Cassina M, Leoncini E, Botto LD, Mastroiacovo P; SAFE-Med Study Group. Treatment of hyperthyroidism in pregnancy and birth defects. J Clin Endocrinol Metab. 2010; 95(11):E337-E341. doi.org/10.1210/jc.2010-0652

61. Foulds N, Walpole I, Elmslie F, Mansour S. Carbimazole embryopathy: An emerging phenotype. Am JMed Genet. 2015;A132A(2):130-135. doi:10.1002/ajmg.a.30418

62. Yoshihara A, Noh J, Yamaguchi T, et al. Treatment of Graves' disease with antithyroid drugs in the first trimesterof pregnancy and the prevalence of congenital malformation. J Clin Endocrinol Metab. 2012;97(7):2396-2403. doi:10.1210/jc.2011-2860

63. Andersen SL, Olsen J, Wu CS, et al. Birth defects after early pregnancy use of antithyroid drugs: A Danish nationwide study. J Clin Endocrinol Metab. 2013;98(11):4373-4381. doi:10.1210/jc.2013-2831

64. Andersen SL, Laurberg P. Antithyroid drugs andcongenital heart defects: Ventricular septal defect is part ofthe methimazole/carbimazole embryopathy. Eur J Endocrinol. 2014;171(5): C1-C3. doi:10.1530/EJE-14-0524

65. Liu H, Wang LL, Zhao SJ, Kwak-Kim J, Mor G, Liao AH. Why are pregnant women susceptible to COVID-19? An immunological viewpoint. J Reprod Immunol. 2020;139:103122. doi: 10.1016/j.jri.2020.103122

66. Weetman AP, Pickerill AP, Watson P, Chatterjee VK, Edwards OM. Treatment of Graves' disease with the block-replace regimen of antithyroid drugs: The effect of treatment duration and immunogenetic susceptibility on relapse. Q J Med. 1994;87(6):337-334. PMID:7913766.

67. National Institute for Health and Care Excellence. Thyroid disease: Assessment and management. https://www.nice.org.uk/guidance/ ng145. Accessed January 14, 2021.

68. Abraham P, Avenell A, McGeoch S, et al. Antithyroid drug regimen for treating Graves' hyperthyroidism. Cochrane Database Syst Rev. 2010; 2010:CD003420. doi:10.1002/14651858

69. Stokkel MPM, Handkiewicz-Junak D, Lassmann JM, Clark LF, Bevan JS. EANM procedure guidelines for therapy of benignthyroid disease. Eur J Nucl Med Mol Imaging. 2020;37(11):2218-2228. doi:10.1007/s00 259-010-1536-8

70. Brandt F, Thvilum M, Almind D, et al. Graves' disease and toxic nodular goiter are both associated with increased mortality but differ with respect to the cause of death: A Danish population-based register study. Thyroid. 2013;23(4):408-413. doi:10.1089/thy.2012.0500

71. Schwensen CF, Brandt F, Hegedus L, Brix TH. Mortality in Graves' orbitopathy is increased and influenced by gender, age and pre-existing morbidity: A nationwide Danish register study. Eur J Endocrinol. 2017;176(6):669-676. doi:10.1530/eje-16-0954

72. Kitahara CM, Berrington de Gonzalez A, Bouville A, et al. Association of radioactive iodine treatment with cancer mortality in patients with hyperthyroidism. JAMA Intern Med. 2019;179(8):1034-1042. doi:10. 1001/jamainternmed.2019.0981

73. Bonnema SJ, Hegedus L. Radioiodine therapy in benign thyroid diseases: Effects, side effects, and factors affecting therapeutic outcome. Endocr Rev. 2012;33(6):920-980. doi:10.1210/er.2012-1030

74. Taylor PN, Zhang L, Lee RWJ, et al. New insights into the pathogenesis and nonsurgical management of Graves orbitopathy. Nat Rev Endocrinol. 2020;16(2):104-116. doi:10.1038/s41574-019-0305-4

75. UK Government, Department of Health \& Social Care. Guidance on shielding and protecting people who are clinically extremely vulnerable from COVID-19. https://www.gov.uk/government/publications/guidance-on-shielding-and-protecting-extremely-vulnerablepersons-from-covid-19/guidance-on-shielding-and-protectingextremely-vulnerable-persons-from-covid-19. Accessed February 1, 2021.

76. Samuels MH, McDaniel PA. Thyrotropin levels during hydrocortisone infusions that mimic fasting-induced cortisol elevations: A clinical research center study. J Clin Endocrinol Metab. 1997;82(11):3700-3704. doi.10.1210/jcem.82.11.4376

77. Samuels MH. Effects of variations in physiological cortisol levels on thyrotropin secretion in subjects with adrenal insufficiency: A clinical research center study. J Clin Endocrinol Metab. 2000;85(4): 1388-1393. doi:10.1210/jcem.85.4.6540

78. John CD, Christian HC, Morris JF, Flower RJ, Solito E, Buckingham JC. Kinase-dependent regulation of the secretion of thyrotrophin and luteinising hormone by glucocorticoids and annexin 1 peptides. $J \mathrm{Neu}$ roendocrinol. 2003;15(10):946-957. doi:10.1046/j.1365-2826.2003.01081 
79. Cintra A, Fuxe K, Wikström AC, Visser T, Gustafsson JA. Evidence for thyrotropin-releasing hormone and glucocorticoid receptor-immunoreactive neurons in various preoptic and hypothalamic nuclei of the male rat. Brain Res. 1990;506(1):139-144. doi:10.1007/BF02686119

80. Alkemade A, Unmehopa UA, Wiersinga WM, Swaab DF, Fliers E. Glucocorticoids decrease thyrotropin-releasing hormone messenger ribonucleic acid expression in the paraventricularnucleus of the human hypothalamus. J Clin Endocrinol Metab. 2005;90(1):323-327.

81. Horby P, Lim WS, Emberson JR, et al; RECOVERY Collaborative Group. Dexamethasone in hospitalised patients with Covid-19: Preliminary report. N Engl J Med. 2021;384(8):693-704. doi:10.1056/NEJMoa2021436

82. Lamontagne F, Agoritsas T, Macdonald H, et al. A living WHO guideline on drugs for Covid-19. BMJ. 2020;370:m3379. doi:10.1136/bmj. m3379
83. Bartalena L, Baldeschi L, Boboridis K, et al. The 2016 European Thyroid Association/European Group on Graves' orbitopathy guidelines for the management of Graves' orbitopathy. Eur Thyroid J. 2016;5:9-26. doi:10.1159/000443828

84. van Vollenhoven RF, Emery $\mathrm{P}$, Bingham $\mathrm{CO}$, et al. Long-term safety of rituximab in rheumatoid arthritis: 9.5-year follow-up of the global clinical trial programme with a focus on adverse events of interest in RA patients. Ann Rheum Dis. 2013;72(9):1496-1502. doi:10.1136/ annrheumdis-2012-201956

85. Kahaly GJ, Bartalena L, Hegedus L, Leenhardt L, Poppe K, Pearce SH. 2018 European Thyroid Association guideline for the management of Graves' hyperthyroidism. Eur Thyroid J. 2018;7(4):167-186. doi:10. $1159 / 000490384$

86. Xia J, Tong J, Liu M, Shen $Y$, Guo D. Evaluation of coronavirus in tears and conjunctival secretions of patients with SARS-CoV-2 infection. J Med Virol. 2020;92(6):589-594. doi:10.1002/jmv.25725 